\title{
Could Toronto provide $10 \%$ of its fresh vegetable requirements from within its own boundaries? Part II, Policy supports and program design
}

\author{
Rod MacRae, ${ }^{\mathrm{a} *}$ Joe Nasr, ${ }^{\mathrm{b}, \mathrm{c}}$ James Kuhns, ${ }^{\mathrm{b}, \mathrm{c}}$ Lauren Baker, ${ }^{\mathrm{d}}$ Russ Christianson, ${ }^{\mathrm{e}}$ \\ Martin Danyluk, ${ }^{\mathrm{f}}$ Abra Snider, ${ }^{\mathrm{g}}$ Eric Gallant, ${ }^{\mathrm{a}}$ Penny Kaill-Vinish, ${ }^{\mathrm{a}}$ Marc Michalak, ${ }^{\mathrm{a}}$ \\ Janet Oswald, ${ }^{a}$ Sima Patel, ${ }^{a}$ and Gerda Wekerle
}

Submitted 11 May 2011 / Accepted 12 July 2011 / Published online 9 February 2012

Citation: MacRae, R., Nasr, J., Kuhns, J., Baker, L., Christianson, R., Danyluk, M., Snider, A., Gallant, E., Kaill-Vinish, P., Michalak, M., Oswald, J., Patel, S., \& Wekerle, G. (2012). Could Toronto provide 10\% of its fresh vegetable requirements from within its own boundaries? Part II, Policy supports and program design. Journal of Agriculture, Food Systems, and Community Development, 2(2), 147-169. http://dx.doi.org/10.5304/jafscd.2012.022.002

Copyright (C) 2012 by New Leaf Associates, Inc.

\begin{abstract}
Urban agriculture in Toronto largely focuses on self-provisioning, but it could be scaled up signifi-
\end{abstract}

Note: An earlier and more wide-ranging version of this paper was published by the Metcalf Foundation as Scaling up urban agriculture in Toronto: Building the infrastructure (Nasr, MacRae, \& Kuhns, 2010).

${ }^{a}$ Faculty of Environmental Studies, York University.

* Corresponding author: 4700 Keele St. Toronto, Ontario M3J 1P3 Canada; +1-416-736-2100 x22116; rmacrae@yorku.ca.

b MetroAg Alliance for Urban Agriculture, http://www.metroagalliance.org.

c Ryerson University Centre for Studies in Food Security, http://www.ryerson.ca/foodsecurity/.

${ }^{\mathrm{d}}$ Formerly Sustain Ontario, now Toronto Food Policy; lbaker2@,toronto.ca.

e Rhythm Communications, RR4 Campbellford, Ontario K0L 1L0 Canada; +1-705-653-0527; russ.c@xplornet.com.

${ }^{\mathrm{f}}$ Geography Dept. University of Toronto.

g Graduate, Food Security Certificate, Ryerson University, now Fresh City Farms. cantly. Our findings in an earlier paper indicate that the supply of land is not an insurmountable barrier. Rather, other more subtle impediments exist, including taxation systems and structures that assume agriculture is a strictly rural activity; inadequate sharing of knowledge among urban producers; limited access to soil, water, and seeds; and the lack of incentives to attract landowners and foundations to provide financial or in-kind support.

The potential exists to develop urban agriculture so that it supplies $10 \%$ of the city's commercial demand for fresh vegetables. Scaling up to this level requires significant policy and program initiatives in five key areas: Increasing urban growers' access to spaces for production; putting in place the physical infrastructure and resources for agriculture; integrating local food production into the food supply chain; creating systems for sharing knowledge; and creating new models for governance, coordination, and financing. Our recom- 
mendations, while focusing on Toronto, offer lessons for those currently attempting to strengthen urban agriculture in other cities.

\section{Key words}

planning, policy and program supports, Toronto, urban agriculture

\section{Introduction}

As is true for many cities in North America, food production in Toronto is primarily an informal provisioning and recreational activity. The city of Toronto has made several policy commitments to urban food production, but has yet to advance an integrated implementation plan to expand commercial production.

In discussions of urban agriculture in Toronto, the explanation for its limited scale is often that the demand for land in the city has remained robust, offering few abandoned or empty lots to accommodate food production. In an earlier companion article, MacRae, Gallant, Patel, Michalak, Bunch, and Schaffner (2010) make the case for scaling up urban agriculture in Toronto and indicate that access to growing spaces (land and rooftops) may not be the major impediment to implementing urban agriculture in Toronto. The study concluded that Toronto required 5,725 acres (2,317 ha) of food production area to meet $10 \%$ of current consumption requirements (based on market purchases). ${ }^{1}$ Of this, 2,653 acres (1,073.5 ha) would be available on:

- existing Toronto farms and lands currently zoned for food production,

- areas zoned for industrial uses (some vacant, some in other uses)

\footnotetext{
1 Ten percent was originally chosen somewhat arbitrarily, but proved to be feasible. Note that this study does not include self-provisioning, since there are no good data on consumption and gardening on which to base an analysis, though such activity could be significant (see MacRae, Gallant, Patel, Michalak, Bunch, \& Schaffner, 2010).
}

- over 200 small plots (between 1 and 4.9 acres or 0.4 and $2 \mathrm{ha}$ ) dotted throughout the northeastern and western parts of the city (most in use, but some vacant).

This area could be supplemented with rooftop production; the maximum rooftop area required would be about $3,072.8$ acres $(1,243.5$ ha), or approximately $25 \%$ of the rooftop area identified as suitable for rooftop greening in the city of Toronto (Banting, Doshi, Li, Missios, Au, Currie, \& Verrati, 2005), though not necessarily appropriate for food production (see discussion below).

Given existing demand for vegetables, a combination of areas cropped more extensively (e.g., potatoes, sweet corn, squash, cabbage) and others grown more intensively ${ }^{2}$ (e.g., lettuce, bok choy) would be required. The land and rooftop space available suggests, however, that there would be difficulties matching parcel sizes with production requirements for key crops, including sweet corn, squash, potatoes, cabbage, carrots, and asparagus.

Clearly, numerous obstacles exist to meeting the scaling-up requirements of urban agriculture in Toronto (see table 1). Hardiness zoning, however, is not an impediment to growing the main vegetables consumed (Canada zone 6, USDA zone 5).

In this paper, we set out to identify the essential features of a program to meet this target, based on the following criteria:

- Builds on existing initiatives, including city programs regarding pesticide reduction and organic waste management;

- Assumes a multi-actor program governance model, with the city playing a key facilitating and often financial role, but with a variety of actors providing leadership and financing;

- Involves progressive implementation over a

\footnotetext{
2 Our presumption here is that intensive production would follow something like the Small Plot Intensive (SPIN) approach; see for example Urban Partners (2007).
} 
10-year period, given the current lack of infrastructure and significant policy and program changes required;

- Focuses on import substitution to minimize competition with Ontario producers;
- Is based on active facilitation of demand supply coordination to optimize the benefits of urban agriculture; and

- Meets other municipal objectives regarding environmental improvement, a livable city,

\section{Table 1. Main Barriers to Urban Farming in Torontoa}

\section{Soil Compost, Safety, Quality}

- Lack of perceived space

- Assessing soil safety

- Site remediation costs

- Suitability of land for farming

- Challenge: Odors from compost, manure

Land Access

- Land-use policies: Selling from city land; public health definition of what constitutes a farm; agricultural zoning; compost regulations

- Short- and long-term land access

- Access to underused land

\section{Land Zoning}

- Regulatory and zoning issues

- Bylaws, lease agreements, jurisdictions

Funding, Resources, Infrastructure

- No resources for new immigrants

- Getting inputs

- Resource sharing

- Farm equipment can't be driven on city roads

- Accessing capital and operating dollars

- Living wage for farmers

- Lack of infrastructure: soil, water, storage, greenhouse

Diversity and Equality (overlap all issues)

- Not equitable if local food is not affordable to everyone

- How are we going to subsidize our food and for what purpose? Is health or justice our focus or frame of reference?

- No place for small farmers (i.e., 1-acre sites)

- Transition from successful backyard gardening to larger-scale production

\section{Marketing, Infrastructure}

- Infrastructure: electricity, storage (cold, dry)

- Problem of food as a commodity; practical training and solutions to making farming lucrative or viable

- Accessing market research

\section{Training}

- Farmer training: business planning, urban farm schools (longer term), support

- Organizational management

- Dealing with bureaucracy

\section{Networks and Communication}

- Building up capacity within urban agriculture

- Strengthening capacity to react to new approaches and get involved in new projects

- Ability to know what is going on in urban agriculture in Toronto

- Better linkages with other urban farming folks in other cities

a Adapted from the minutes of the meeting of 17 November 2008, of Toronto Urban Growers 
and employment opportunities. Toronto has a Food Charter, is preparing to adopt an associated Food Strategy, and identifies local food procurement and production as key actions in its climate change mitigation and adaptation strategy (City of Toronto, 2008). Urban food production is viewed as an integral part of all these strategic developments, yet the potential for urban agriculture is nowhere near being fully realized.

Ultimately, the task is to build the infrastructure for commercial food production. Infrastructure here is understood in its broadest sense as the structural elements that underpin urban food production and either hinder its development or enable it. We offer proposals in five areas:

1. infrastructure for accessing spaces for production;

2. resources, services, and physical infrastructure;

3. food-chain infrastructure;

4. knowledge infrastructure; and

5. governance, coordination and financial support infrastructure.

\section{Some Conceptual Considerations}

The approach taken in this study is informed by a number of conceptual frames. This paper makes proposals on how an alternative future might be achieved. Future scenario studies around food and agriculture (cf. Desjardins, MacRae, \& Schumilas, 2010; Nassauer, Corry, \& Cruse, 2002; Seccombe, 2007) serve a number of purposes: they describe an alternative to a current situation; they can show the potential implications of new policy directions; and they can identify the potential policy instruments to achieve a new future. This study attempts to accomplish those purposes, as it relates to commercial urban food production in the city of Toronto. Note, however, that future scenario studies cannot rely on traditional conceptions of evidence, but rather are informed by experiences from other jurisdictions, numerous analytical frames, and a specific policy context.

This work is also informed by foodshed analysis. The conceptual terrain has been set out by Kloppenburg, Stevenson, and Hendrickson (1996), who argue that this metaphor taken from watershed analysis can serve as a conceptual and methodological unit of analysis for food studies. One of the questions asked in a foodshed analysis is whether a region optimizes its ability to draw food from within its own foodshed, before relying on imports to meet deficits. Peters, Bills, Lembo, Wilkins, and Fick (2009) have applied this approach to foodsheds around cities in New York State, concluding that midsized cities could meet $84 \%$ to $98 \%$ of their current nutritional requirements from within 32 miles $(51 \mathrm{~km})$. However, they found that New York City would be largely unfed from New York State suppliers (only 2\% of requirements) in this scenario, and the average transport distance would be 164 miles $(264 \mathrm{~km})$. Scaling up urban food production, not explicitly part of their study, adds another dimension to this frame and modeling.

The practice of urban agriculture proposed in this analysis is a product of agroecological theory, the conceptual foundation for sustainable food production (MacRae, Hill, Henning, \& Bentley, 1990). This frame has guided proposals on size of parcels, production methods, and distribution scenarios (discussed both in MacRae, Gallant, et al., 2010 and below).

A related conceptual frame is that of organizational ecology. Organizations and organizational alliances have been recognized for some time as having their own ecology (Morley \& Wright, 1989; Plumptre, 1988) - an ecology that can potentially mimic that of the systems and processes with which the organization or alliance is concerned (Morgan, 1989; Solway, 1988; Walters \& Holling, 1984). We use this framework to guide the proposals for new organizational forms and governance approaches to advance urban agriculture in Toronto. 
In constructing these proposals, we reviewed primary documents relevant to Toronto and secondary literature from other jurisdictions, conducted interviews with key informants, and carried out a web-based survey ${ }^{3}$ of those on the mailing list of the Toronto Urban Growers (TUG) network, receiving more than 30 responses, a response rate of $45 \%$. Based on these diverse sources, we developed the five areas of intervention proposed here, which we will detail next.

\section{Infrastructure for Accessing Spaces for Production}

Using high-cost urban land for food production is a challenge, given dominant urban planning and real estate practices. Urban farmers need stable access to land, some of which needs to be secure for the long term. Ensuring such access will involve changes to official plans, zoning bylaws, and land taxation on the part of government, and ownership or lease arrangements on the part of landowners.

\section{City of Toronto Official Plan and Zoning Bylaws}

The city of Toronto's Consolidated 2010 Official $\operatorname{Plan}^{4}$ contains policies dealing with community and rooftop gardens, including references to gardens in parks and rooftop gardens in multi-unit residential developments. These policies are bolstered through repeated reference to rooftop and community gardens in the nonpolicy text of the Official Plan. They are referred to as part of creating beautiful cities (1.2), as an ingredient in the creation of a high quality public realm (2.2.2), as offering opportunities for passive and active recreation (2.3.2), as an important community facility through which the city and local agencies deliver services (3.2.2), and as part of the diverse and complex system of open spaces and natural areas (2.2.3).

\footnotetext{
${ }^{3}$ The results of the survey are found at http://urbangrowers. wordpress.com/knowledge-library/. TUG was formed in 2008 to serve as an umbrella group for urban farmers, advocates and researchers across Toronto. A listserv for TUG members can be found at http://groups.google.com/group/torontourban-growers.

4 The plan can be viewed at http://www.toronto.ca/planning/ official plan/introduction.htm.
}

Despite the presence of several hundred hectares of agricultural land within the Rouge River Park in northeast Toronto and other patches of land in the city that are zoned for food production (see MacRae, Gallant, et al., 2010), the Official Plan has only two policies that deal with agriculture:

- Policy 2.1.1(k) states that the city of Toronto will work with its neighboring municipalities to develop a framework for dealing with growth across the Greater Toronto Area that, among a number of other priorities, protects the region's prime agricultural land.

- Policy 4.4.2 notes that agriculture is an acceptable secondary use within utility corridors.

Official Plan land use designations set broad categories of permitted and intended uses on private and public city lands. Zoning bylaws implement these objectives at the site level. They contain site-specific regulations pertaining to land use, and to the size, height, density, and location of buildings. The Planning Act requires that zoning bylaws conform to the Official Plan.

The city of Toronto is currently in the process of updating its zoning bylaws to conform to its new Official Plan. The project has distilled over 1,550 land use definitions into 180 across nine categories: residence, public, commerce, performance, industry, parking, institution, administrative, and accessory. Agriculture is not identified as a category. However, two of the 180 land use definitions, both of which are in the Industry category, are agriculture-related.

- Agricultural Uses: "Premises used for growing and harvesting plants or raising animals, fowl, fish or insects, and may include aquaculture.... The definition of agricultural use should be broad enough to capture the range of uses anticipated. An agricultural use is the cultivation of plants and the raising of animals primarily for food." 
- Market Garden: “A market garden is an area that is used for the growing of plants. A market garden is not on a residential property. Lands such as Hydro corridors or roof tops could also be used for growing food and plants."

Could sites recommended for food production be rezoned to one of these two new designations? Given current political realities, this seems unlikely in the short term, but there appear to be several options, if a permanent food production designation is not approved.

- A minor variance application may be brought to a municipal Committee of Adjustment. This process can take up to three months to complete and costs at least $\mathrm{C} \$ 500$. Permission given is not specific to the use of the land, but more to the structures on and configuration of the land. The duration of the land use can be specified in the application.

- A temporary use bylaw, permitted under the Toronto Official Plan, may be used to zone land or buildings for specific uses for a maximum of three years, with possible extensions. A temporary use bylaw is initiated by the city and includes public consultation; it can take up to one year to complete. It is more specific to the land use of the property in question. The cost is considerably more than a minor variance.

How could the Official Plan and zoning bylaws better support urban agriculture? The key challenge is to permit food growing on lands not covered by current categories. MacRae, Gallant, et al. (2010) identify 90 potential sites in the Industrial zoning category. The two proposed land use definitions (Agricultural Uses and Market Garden) will need to be widely permitted across Industrial zones to allow for cultivation at this scale.

The MacRae, Gallant, et al. study also identifies 75 production sites that are currently designated as Open Space. Agriculture would be a permitted use in Open Spaces zones under the new draft zoning bylaws. ${ }^{5}$ The Toronto Parks, Foresty and Recreation Department would need to develop a more flexible approach to food production in open spaces than its current policy displays. Because urban agriculture can fulfill numerous municipal objectives, an argument can be made that private gains will achieve public purposes and therefore should be permitted.

Forty-three sites identified in the MacRae, Gallant, et al. (2010) study currently have commercial, institutional, and residential designations. Temporary use permits, minor variances, or interim control bylaws are possible tools to use for these sites, although the time and expense associated with putting them in place may prevent their use for agriculture. A coordinated and funded program by the city to lighten the burden on urban farmers and community organizations would make this a more useful approach. In the longer term, language to support community gardening and the planting of fruit trees across most zoning designations could be included in future official plans and zoning amendments. ${ }^{6}$

Long-term success would likely be facilitated by changes to the Official Plan and zoning designations to include an Urban Agricultural and Garden zoning designation, as exists in several U.S. cities, including Philadelphia (Caggiano et al. 2009) and Cleveland. ${ }^{7}$ The ideal would be permanent protection of the agricultural status of certain lands. Montreal's Permanent Agricultural Zones (PAZ) are an example of this approach. Four percent of the city's lands are zoned under this category, including an experimental farm, an agricultural park, an eco-museum, and an arboretum (True Consulting Group 2007). Though the PAZ does not extend into the urban core, its existence on the

\footnotetext{
${ }^{5}$ Note that a related discussion about the potential sale of food produced in parks, through farm stands, and related marketing approaches, is also a priority.

${ }^{6}$ Conditional use permits allow agriculture in most land use designations in Oakland, California (McClintock and Cooper, 2009).

${ }^{7}$ See http://www.mayorsinnovation.org/pdf/Cleveland CG zoning ord.pdf.
} 
urban fringe keeps speculators at bay and by its permanence "permits farmers to risk investment" (McCallum, 2001, p. 3).

\section{Agricultural Land Taxation}

Land taxation is a key issue for urban agriculture on private land. Wekerle (2002) has argued previously that shifting tax burdens could encourage urban agriculture if small lots used for food production could be taxed at an agricultural rate

Although zoning is largely a city issue as it relates to land use, and although it is the city that collects and uses the property taxes, farm designation for property tax purposes is in provincial hands. To obtain a reduced property tax rate, a property must be taxed at agricultural rates. The Farm Property Class Tax Rate is offered through the Ontario Ministry of Agriculture, Food and Rural Affairs (OMAFRA), and the Municipal Property Assessment Corporation (MPAC) is responsible for determining the property classification. Currently, to obtain a farm designation the property must be assessed as farmland. A landowner ${ }^{8}$ must request a designation reconsideration by MPAC and an eligibility determination from OMAFRA and approval for the Farm Property Class Tax Rate. The owner must have a Farm Business Registration Number and the farm must generate at least $C \$ 7,000$ in gross annual income. The owner is responsible for ensuring that any tenant who farms the land has a valid Farm Business Registration Number.

If the site receives this designation, its tax rates are reduced to $25 \%$ of residential property tax rates. The farm rate applies only on the part of the land under cultivation. There are farms within Toronto with a Farm Business Registration Number that are taxed at the agricultural rate. An urban location may not then, per se, be an obstacle to reduced tax rates. But small-scale urban farms may have more difficulty obtaining a Farm Business Registration Number. Exemptions from the normal requirements may be needed. OMAFRA should examine

\footnotetext{
${ }^{8}$ If the property is owned by a business that is a sole proprietorship, the owner must be a Canadian citizen or permanent resident.
}

whether small-scale urban farms might need a different minimum gross annual income for eligibility ${ }^{9}$ for a farm business registration number, and MPAC and OMAFRA should also study the implications of establishing a small-scale urban farm designation.

Following from the MacRae, Gallant, et al. (2010) analysis, the city finance department would need to study the tax revenue implications of permitting urban farm property tax reductions on the properties identified in the report. The implications for land owned or controlled by the provincial or federal governments or agencies are potentially problematic. For example, establishing production sites in hydroelectric corridors has tax revenue implications for the city of Toronto, since it results in a lower tax rate relative to the standard corridor rate (Danyluk, 2009).

Given these potential complexities, implementing land use designation and tax changes through a coordinating and facilitating body (see discussion of governance below) to help with the processing of applications could make the process more efficient and affordable for participating landowners.

\section{Lease Arrangements}

Urban farmers and growers often do not own the land they cultivate. Urban farming requires arrangements that provide security of tenure and suitable financial arrangements (if required) for all parties, cover insurance and liability issues, and include conditions of use that would support the city's multiple environmental and sociocultural objectives.

Depending on the nature of the food production, leases could be with individuals or organizations. Setting lease rates has already proven to be a challenge in some instances in Toronto. Setting rates is complex when having to determine "fair market value" for land with a limited set of private

\footnotetext{
${ }^{9}$ For example, the FoodShare production site grosses C \$6,000/0.1 ha of land (Danyluk, 2009).
} 
uses (e.g., hydroelectric corridors), or if it could potentially be used for housing development.

Landowners may have motives other than maximizing profit for offering land at reduced rate or even for free. They may want to see food production next to their residence, to support the local food movement, to gain environmental benefits (birds, bees, etc.), or to obtain a tax break by making land available to nonprofit or public groups. If the city creates incentives for developers to install food production sites, and disincentives if they fail to, it can shift market incentives toward allocating more land to such purposes (personal communication, W. Seccombe, Everdale Environmental Learning Centre, 2010).

Among the 312 parcels identified in the MacRae, Gallant, et al. (2010) analysis are a wide range of likely landowners and food production options. Given the need to coordinate production and distribution, and the expertise required to manage a complex set of arrangements, a coordinated leasing system will be needed. Interested landowners, including the municipal government, could contract with a third-party organization to manage lease arrangements based on templates established by the municipality. The third party would set up the lease arrangements with interested farmers, taking a small percentage of rents supplemented with revenues from the municipality and foundations to finance its coordination activities. If a third party is managing leases, there is some opportunity for pooled leasing rates for farmers and community organizations, with the leasing agency pooling revenue and then dispersing it differentially to landowners.

The use of such third-party arrangements, whereby governments subcontract to a nongovernmental organization (NGO), is increasingly common. Ontario NGOs are experimenting with such arrangements, with the partnership between FarmStart and the Toronto and Region Conservation Authority (TRCA) to run a farm incubator program being one example. Several Toronto private and nonprofit organizations are starting to explore innovative ways to establish agreements for accessing potential lands for production, including individual backyards.

In addition to setting out the rental and stewardship conditions for the land (e.g., organic production to respect pesticide use restrictions and greenhouse gas mitigation objectives, and respecting biodiversity enhancements), the leases would require that food is distributed to markets within the municipality in ways that minimize negative environmental impacts (e.g., short-haul trips, bicycle delivery where feasible, or coordinated trucking to aggregate loads).

\section{Infrastructure for Rooftop Agriculture Development} A few Toronto rooftops are already food-growing spaces. Without significant interventions, aboveground food production (including on roofs) will likely continue to expand, but on a very small scale and on a noncommercial basis. Large-scale commercial rooftop agriculture is probably still years away from being practiced widely because the barriers are significant (e.g., existing rooftop designs, roof access issues, or unclear lease and liability issues).While individual examples of commercial rooftop farms such as the Eagle Street Rooftop Farm and Brooklyn Grange in New York do exist, they remain exceptional.

Rooftop food production can take many different forms, from intensive green roof gardens to container and raised-bed gardens, but most policy initiatives target green roofs rather than food production. No cities have specifically targeted rooftop production as part of an agricultural development strategy, but given the scarcity of land and competing uses, it is likely only a matter of time before rooftops are put to more intensive use.

MacRae, Gallant, et al. (2010) identified the need for 3,072.8 acres (1,243.5 ha) of rooftop growing space to meet the target of $10 \%$ of Toronto's fresh vegetable supply, or about $25 \%$ of the rooftop space theoretically identified as being appropriate for rooftop greening (Banting et al., 2005).

Toronto is moving to take greater advantage of its rooftops with a new green roof bylaw. As of January 31, 2010, new residential, commercial, and 
institutional buildings are required to have a certain percentage of green roof coverage. ${ }^{10}$ This provision applies to all new construction with a gross floor area of 21,528 square feet $\left(2,000 \mathrm{~m}^{2}\right)$ and over (and, for residential buildings, a height of 66 feet $(20 \mathrm{~m})$ and over). The coverage required begins at $20 \%$ for smaller buildings, and increases to a maximum of $60 \%$ as the gross floor area increases to 215,278 square feet $\left(20,000 \mathrm{~m}^{2}\right)$ and over. Industrial buildings were exempt until 2011, after which they are required to have approximately 10 percent coverage.

However, substantial changes would be required to the current bylaw to support food production. When initially proposed by the city, one of the stated goals of the bylaw was to "increase opportunities for urban food production" (City of Toronto, 2005), but the current bylaw is unlikely to accomplish this. It is focused on environmental benefits and aims to reduce the urban heat island effect (the higher temperatures found in urban areas caused by the sun reflecting off hard surfaces) and improve stormwater management (rainwater run-off from buildings). A policy that was meant to encourage rooftop food production would have to address a number of issues (Kaill-Vinish, 2009), including:

- Design elements: food production usually requires deeper soil than that required under the Toronto bylaw, and a substantial amount of rooftop production tends to be done in containers;

- Access to the roof: growers need daily access to the roof during the growing season and the capacity to readily move material up and down;

- Insurance: coverage for growers using the rooftop will be needed;

- Wider applicability: policies should encourage retrofitting existing roofs rather

10 The bylaw was enacted 27 May 2009. See http://www.toronto.ca/legdocs/bylaws/2009/law0583.pdf. than just applying to new construction only, as in the Toronto example;

- Zoning: questions about zoning the land to allow for food production on the roof will need to be settled; and

- Construction code: some requirements may need to be adapted to the conditions of rooftop food production.

Various policy tools also have been used to encourage green roofs in other jurisdictions. These include bylaws, density bonuses, incentive programs, grants, fees, and levies (usually related to stormwater run-off from buildings). Some of these same policy tools potentially could be harnessed to target increased rooftop food production. Given Toronto's current policy and program infrastructure, the next challenge is to study how to modify existing instruments to promote food production. If modifying existing policies and programs proves too difficult, a specific food production bylaw, which includes attention to rooftop spaces, might have to be introduced.

\section{Resources, Services, and Physical Infrastructure}

"Physical infrastructure" covers all that is useful for the production, processing, and distribution of food in urban areas. When we asked urban growers about the resources on which they rely most to produce food in the city, the top three were (1) seeds, (2) land or space, and (3) compost. Ranked somewhat lower were water, soil, funding, and seedlings. When asked what resources they most lacked, the five top responses were (1) compost, (2) funding or capital, (3) land, (4) staff or volunteers, and (5) soil. The main explanations given for identifying certain tools and resources as particularly lacking were: (1) accessibility, (2) organic matter, (3) affordability and funding, (4) knowledge, and (5) tools.

\section{Soil and Amendments}

Toronto sits upon some of the most productive soil in Canada, so for some growers soil quality is not much of an issue, provided there has been no 
extensive disturbance from urban processes. Yet access to soil and ways to improve its quality show up among the top issues for those involved in food growing. Most new sites where urban agriculture is feasible require testing and some transformation in a coordinated and environmentally sensitive way. Even where high-quality soil is available, it may be difficult to access or use, primarily due to real or perceived soil contamination. Part of the solution to soil contamination is technical (developing appropriate means for soil decontamination), but large-scale technical intervention goes beyond the capacity of many individual gardeners and producers. Toronto Public Health's Environmental Protection Office is currently developing a soil assessment protocol to assess the potential risks, to be used in the future for lands considered for urban agriculture.

A larger question is who will pay for soil remediation. Given the costs, urban agriculture will only occur on sites with minimal to moderate contamination that can be remediated with composting and phytoremediation (using plants themselves to absorb pollutants).

Soil is also needed for rooftop gardening. ${ }^{11}$ The development and dissemination of appropriate, affordable, lightweight techniques for both soilbased and soil-less cultivation are needed. Local organizations, such as Alternatives and Earthbox, have developed appropriate growing media and containers, yet such approaches are rarely applied. A strategy is needed to promote the development and adoption of such growing approaches.

In urban areas, just as in rural ones, amendments are applied constantly to improve the soil, and pesticides are applied frequently to manage pests. In Toronto, however, what can be applied in gardens is increasingly restricted, notably due to the provincial ban on the sale and use of chemical

\footnotetext{
${ }^{11}$ Many examples of alternative forms of containers and stands for off-soil cultivation were featured in the Carrot City exhibit. See http://www.carrotcity.org, particularly the Products section.
}

pesticides for cosmetic purposes, ${ }^{12}$ which supplanted the earlier ban by the city of Toronto. ${ }^{13} \mathrm{At}$ the same time, obtaining organic alternatives for fertilization and natural pest management is a challenge requiring attention from organizations and the municipal government.

\section{Compost}

Toronto has substantial amounts of viable organic materials at its disposal for composting because of its green bin and yard waste collection programs.

Yet in our survey, compost tops the list of resources that are needed to expand urban agriculture. Most respondents recommended an improved compost distribution system, involving an expansion in local producers and the set-up of numerous locations for pick-up in the city. Other respondents suggested better information, including workshops, a public list of suppliers, and the streamlining of municipal assistance.

The problems start with the quality of what goes into Toronto's green bins and with its processing. In response to the shortage of local landfill sites, the city has placed a singular priority on landfill diversion, without coupling this goal with nutrient recycling. The solid waste department operates with neither a requirement nor a budget for ensuring that the end product is quality compost to be used in food growing (personal communication, Wally Seccombe, Everdale Environmental Learning Centre, 2010).

Moreover, current rules dictate that yard and leaf compost is available only to residents, not sold to businesses (City of Toronto, 2009). With limited

\footnotetext{
${ }^{12}$ Regulation 63/09, made under the Pesticides Act, came into effect on Earth Day, April 22, 2009. It bans the use and sale of cosmetic pesticides across the province and supersedes any municipal bylaws or regulations on pesticides. Specifically the ban refers to usage on lawns, gardens, parks, and school yards. Some qualifications and exemptions exist, for example, agriculture, West Nile virus control, golf courses, and poisonous-to-touch plants, such as poison ivy. It remains unclear how the rules might affect commercial-scale urban production, but we presume that eliminating pesticide use would be preferable.

${ }^{13}$ See http://www.toronto.ca/health/pesticides/faq.htm.
} 
supply, this makes sense; yet this product has acquired among community gardeners a reputation for poor quality (excessively high C:N ratio, too many contaminants), so it is underutilized. Were the city to bag and sell its compost, it would have to guarantee its quality for soil amendments for growing food, as happens already in some American cities.

Given that most urban farms occupy a very limited area and are uniquely plant-based operations (without access to sources of nitrogen needed for better quality compost, partly because of the municipal ban on raising farm animals in the city ${ }^{14}$ ), making quality compost based only on organic matter generated on site is usually not feasible. Currently, any operation importing materials for on-site composting requires approval by the Ontario Ministry of the Environment to operate as a waste disposal site - a difficult and expensive process. The ministry needs to develop a simplified and less expensive mechanism, while continuing to control the content and process of imported materials for on-site composting. Composting is even more challenging on rooftops, because of the difficulty of getting materials to and from the roof.

A co-operative group could take on the role of coordinating the purchase and distribution of the inputs for composting, as well as handle the associated approvals. Such an organization could be a bulk purchaser of compost materials and other inputs (see discussion below on an urban growers' cooperative). An alternative to large-scale composting are medium-scale composting facilities centralized composting sites located within different communities. Medium-scale composting is at the heart of the mission of FoodCycles, a new organization that seeks to combine composting from and for the neighborhood with production, marketing, and education relating to food.

The medium-sized approach is very recent in Toronto and may develop significantly in the

\footnotetext{
${ }^{14}$ Note there is a movement in Toronto to overturn the ban on livestock, but it is not yet clear whether it will be successful.
}

future, ${ }^{15}$ but until that takes place, sufficient quality compost for an expanding urban agriculture will need to be generated through large-scale composting based on improvements in the green bin program (especially since it is in the process of expansion to apartment buildings ${ }^{16}$ ). There is thus a real need to accommodate a wider range of composting operations at all scales, and to change the rules to accommodate them, in order to ensure proper nutrient cycling while providing reliable local sources of compost for a thriving urban agriculture industry.

\section{Water}

A challenge for the city of Toronto is how to encourage the creation of gardens and cropping systems while reducing demand for water. This means mulching, using soils with good moistureholding capacity, cultivating drought-resistant plant varieties, and incorporating plants that offer shade. The need for water will depend on the type and design of the operation.

If city hook-up is required, a crucial question is whether the farm operation must be connected to a drip irrigation system and metered. Most growers prefer drip irrigation systems with full coverage. Portland, Oregon, reported that it cost US\$20,000 to US $\$ 30,000$ just to meter sites for urban agriculture (Mendes, Balmer, Kaethler, \& Rhoads, 2008), a substantial sum. Policy will need to address how to service urban farm sites with water, and who will bear those costs.

Of course, not all water for irrigation must be brought from off site. Over half of the respondents in the survey reused water, mostly from rain barrels. More advanced water-reuse systems such as cisterns and greywater recycling arrangements are almost non-existent in Toronto. ${ }^{17}$ For those

\footnotetext{
15 A new report (Vidoni, 2011) focuses on evaluating what it would take to initiate community composting projects in Toronto, looking at examples from elsewhere for lessons. ${ }^{16}$ See http://www.toronto.ca/garbage/multi/green bin program.htm.

${ }^{17}$ One exception is The Stop's Green Barn, where a greywater capture system was included as part of the retrofitting of a historic building. See http://thestop.org/green-barn.
} 
who do not reuse water for irrigation, we asked what would encourage them to start reusing water. This question yielded two main responses: (1) guidance (through workshops and other forms of education) to navigate the process of getting a rain barrel or other system for using recycled water; and (2) financing.

These responses indicate a readiness to use alternative approaches and avoid reliance on domestic, treated municipal water. Other cities already have well established programs expanding water catchment facilities. GrowNYC has helped install rain barrel systems at over 60 community gardens in New York City. ${ }^{18}$ The expansion of urban agriculture in Toronto will need to be tied in closely to the city's existing rain barrel initiative, but other strategies should also be investigated, including rain gardens, swales, and neighborhoodbased rain storage (cisterns).

\section{Power and Lighting}

Power supply is often overlooked as a part of modern urban agriculture. Cultivation itself may not require electricity (one major exception being hydroponics), but many support functions do, from refrigeration to lighting for processing spaces, to ventilation of greenhouses in the summer, to record-keeping. Lighting may also be important for safety and security and for harvesting at dawn or dusk.

For many potential production sites, a power supply may already be nearby. Bringing power to rooftops is usually straightforward. However, a number of sites around Toronto do not have ready access to power. Ironically, electric transmission corridors, which are often used for cultivation, seldom have a supply of electricity on the ground.

Where power needs to be brought in, one question is whether permanent or temporary service is appropriate. The latter might seem to make sense if there is no off-season production between November and April. However, temporary hookup rates can be higher than those for regular

${ }^{18}$ See http://www.grownyc.org/openspace/rainwater. connections, and as many growers move towards season extension, permanent connections would be advisable.

As inexpensive, small-scale solar panels become increasingly common, solar energy may become a perfect fit for urban agriculture. Other power efficiency opportunities include integration of compost and fish farming into greenhouses to catch the heat released (as practised by Growing Power in Milwaukee, Wisconsin), the use of wasted energy from buildings, and improved greenhouse and cold storage design.

\section{Seeds and Seedlings}

Relative to many other cities, the production system for seeds and seedlings is relatively well developed in Toronto. The responses to our survey confirmed that there are many ways to obtain seeds and seedlings, including seed saving, retail stores, seed exchanges, and the Internet. For example, Urban Harvest, a small commercial producer of seeds and seedlings, serves the local market, growing most of its seeds and seedlings inside the city.

Yet beyond specific venues, such as some farmers' markets and seed exchange events, most producers do not have ready access to seeds and seedlings where and when they need them. What is available at neighborhood supply centers is typically a very narrow range of the most common herbs and a handful of vegetables. The seeds and seedlings for more specialized produce consumed by particular cultural groups are especially difficult to locate.

The space for producing seeds and seedlings within the city remains inadequate. Many growers cited a shortage of greenhouse space in the city, which is crucial for getting seedlings ready for planting season. Even established producers like Urban Harvest have to shift production sites frequently, as tenure insecurity and shortage of reliable growing space force them to move constantly and in many cases settle by necessity outside the city.

A systematic enhancement of the production and distribution of seeds and seedlings across the city 
will be necessary to scale up urban agriculture. Support for the producers of seeds and seedlings will range from enterprise development assistance to greenhouse provision or long-term leases on institutional land. On the distribution side, urban agriculture hubs (discussed below) could help make seeds and seedlings more readily available to city residents. At the same time, working with the owners of small, family-run neighborhood garden centers can provide an expanded range of choices for the small urban producer.

\section{Production Equipment and Facilities}

We asked about the tools that growers rely on to produce food in the city and about those that are needed but particularly lacking. The top responses were largely basic tools: hoses, wheelbarrows, pitchforks, shovels, composters, stakes, trellises, and rain barrels. The most sophisticated item mentioned was automated/drip irrigation.

Clearly, the need for basic tools cannot be underestimated in the spread of urban agriculture, especially for the many small plots identified in the MacRae, Gallant, et al. (2010) analysis. Food cultivation involves many different tools, and their cost can add up. At the same time, not all tools are needed simultaneously. Co-operative sharing arrangements could buy such equipment in bulk and make them available through travelling toollending libraries, including hand tools, rain barrels, fencing, protective meshing, irrigation lines, and packaging. ${ }^{19}$ Sophisticated hand tools are also very useful for rooftop agriculture, where moving larger equipment can be quite difficult.

\section{Security}

Kaufman and Bailkey (2000) reported that urban farmers view the theft of food as primarily an irritant rather than deterrent. While theft may not be an issue on most sites, it does come up regularly as a top concern at gatherings of community

\footnotetext{
${ }^{19}$ A new venture, Fresh City Farms, is making available such a collective resource to the franchise farmers who were to take part in this enterprise in summer 2011. Participating farmers would have access to a collection of tools that is shared between them.
}

gardeners (personal communication, Rhonda Teitel-Payne, The Stop Community Food Centre, 2010). ${ }^{20}$ This is addressed by fencing, though the expenses and negative image associated with fencing may be a deterrent to its use. In many public park settings, fencing is simply not an option. Alternative measures such as the use of "living fences" (shrubs, berry bushes, etc.) can be quite effective..$^{21}$ A communication strategy and education campaign can also be helpful.

Although food production site often result in greater community safety (more eyes on the street), urban farmers have occasional concerns about personal security that are serious. A security survey would need to be carried out for many parcels and a prevention plan developed. Alarms and security fencing may be required in some cases; such measures should be considered part of the municipal investment in infrastructure. Operation Greenthumb, a unit of the city of New York, provides fencing for new community gardens.

Fencing is also needed for rooftop food production as a matter of liability. Regulations that govern the type, placement, and height requirements related to fencing, as well as who would use the area and when, how close to the edge of the roof a garden may extend, and what materials may be used, vary depending upon the site and ownership (e.g., school buildings have to follow rules set out by the local school board, whereas municipal buildings have a different set of regulations). Lack of knowledge of these requirements and the fear that they may be too burdensome appear to be holding back rooftop production in Toronto (Nasr et al., 2010).

\section{Food-Chain Infrastructure}

Given the city of Toronto's interest in urban agriculture as a greenhouse gas mitigation strategy,

\footnotetext{
${ }^{20}$ FoodCycles, for instance, had one instance of vandalism to its greenhouse in its first year of operation at Parc Downsview Park in Toronto. Since then, a recurring problem has been the theft of its produce rather than damage to its facilities.

${ }^{21}$ Such a strategy is being adopted in the design of the new park to be created at the heart of the redeveloped Regent Park neighborhood.
} 
there is little advantage in taking markets away from existing regional producers, whose transportation of food typically contributes less to greenhouse gases than that of the dominant longdistance producers. Established farmers have traditionally opposed commercial urban agriculture because of worries, real or perceived, that it will cut into their markets. Given such concerns, it makes sense for urban production to focus on supplanting vegetables shipped long distance by truck. The potential environmental benefits of local production will be realized only with careful attention to minimizing transport with small vehicles, which emit more carbon dioxide per unit of food moved than large trucks, trains, or ships (Edward-Jones et al., 2008).Toronto is a major destination for California and Florida vegetables, most of them trucked. This means that a municipal and provincial strategy must intervene in supply-chain dynamics in ways that are not traditional for Canadian governments.

\section{Import Substitution}

Identifying import substitution opportunities is a significant challenge, given the current deficient state of market intelligence on the subject. We know from more general data that in 2001 Canada imported $86 \%$ of the fruit and $39 \%$ of the vegetables (excluding potatoes) it consumed. ${ }^{22}$ In recent years Canada has been importing around 1.8 million U.S. tons (1.6 million tonnes) of fresh vegetables (excluding potatoes), with over $70 \%$ of that typically coming from the United States. ${ }^{23}$ The top 10 imports by volume or value are typically lettuce, tomatoes, melons, peppers, carrots, onions, broccoli, celery, cauliflower, and gherkin cucumbers, accounting for $75 \%-85 \%$ of total fresh vegetable imports. ${ }^{24}$ Some $55 \%$ of fresh vegetable imports to Canada come into Ontario. In a background analysis for the Food and Hunger Action Committee, City of Toronto (2001), MacRae used 1999 data to determine that for the top 10 vege-

\footnotetext{
22 Derived from Statistics Canada (2001).

${ }^{23}$ See http://www4.agr.gc.ca/resources/prod/doc/ misb/hort/ sit/pdf/veg02 03 e.pdf.

${ }^{24}$ See http://www4.agr.gc.ca/AAFC-AAC/display-afficher. $\underline{\text { do?id=1220616635495\&lang }=\text { e\#tab } 310 .}$.
}

tables, 38\% arrived during Ontario's growing and early storage season (June-November), most of that coming from the U.S. ${ }^{25}$ The import substitution target for Toronto production would, thus, be to replace $5 \%$ of fresh vegetable imports into Ontario during its prime growing and storage season, ${ }^{26}$ a relatively modest import substitution target.

But not all the import substitution would be targeted to U.S. sources. For example, Ontario produced about $7 \%$ of Canadian potatoes on about 38,150 acres (15,440 ha) in 2006. MacRae, Gallant et al. (2010) calculated the need for 1,206 acres (488 ha) of potato production, which seems modest except that the planted area of potatoes has been in gradual decline since $2003,{ }^{27}$ likely due to changes in consumption patterns and national overproduction. Fresh potato imports measured 211,937 tons (192,266 tonnes), mainly in the Mayto-July period, with $64 \%$ of those coming in from Washington and California (Agriculture and AgriFood Canada (AAFC), 2007). It would be unlikely that Toronto potato production would substitute for the U.S. product, since the storage season does not usually extend into this period. Instead, it would likely compete with imports from other regions of Canada, particularly Prince Edward Island and New Brunswick, or could represent a new specialty organic potato market.

A more complicated question is posed by the relationship between conventional and organic markets, since promoting organic production ${ }^{28}$ will be critical to meeting Toronto's greenhouse gas and pesticide reduction targets. These are not directly substitutable, as there are often price, quality and variety or breed considerations that determine whether a conventional buyer will shift

\footnotetext{
25 Over $90 \%$ of it did for most of this period, and imports from Mexico and South America typically pick up in October and November.

${ }^{26}$ Calculated by taking $10 \%$ of the $38 \%$ and dividing by $75 \%$. ${ }^{27}$ See http://www.omafra.gov.on.ca/english/stats/hort/ potato.htm.

${ }^{28}$ For an overview of the benefits of organic vs. conventional production related to GHG emissions, see MacRae, Lynch, \& Martin (2010).
} 
to organic purchasing. Unfortunately, there is not much data on organic imports except that it is estimated that somewhere between $60 \%$ and $85 \%$ of Canadian organic consumption is imported largely from the U.S. ${ }^{29}$ In contrast, only $30 \%$ of conventional foods to meet domestic requirements are imported (AAFC, 2008). A presumption of this study is that it will be feasible for organic vegetables to supplant conventional markets, but this will not occur without significant marketing efforts. ${ }^{30}$ Providing more sophisticated market intelligence would be a critical task for a successful program, and it could be undertaken by an urban growers' marketing co-operative (see below).

\section{Post-harvest Handling and Processing}

For commercial growing operations, sophisticated post-harvest facilities and mechanisms for food packaging, processing, and distribution are needed. High quality, safe, appealing produce grown locally would likely foster market interest in Toronto production. It is now well recognized that the "middle" of the food chain (processing, storage, and distribution) represents the most significant bottleneck in developing alternative food systems. ${ }^{31}$ Developing an array of such facilities is vital for supporting commercial-scale urban agriculture in Toronto. Yet the expansion of the "middle" in an urban context poses particular challenges.

Currently there are few post-harvest handling facilities in Toronto. Post-harvest facilities include cooling units to take the field heat out of produce, space and materials for packaging, and, in some

\footnotetext{
${ }^{29}$ Based on organic industry analysis and Nielson Company (2006).

30 There is a legitimate question about the impacts of 5,725 acres (2317 ha) of organic vegetable production, should all Toronto acres be certified. Macey (2006) reported 1,166 acres (472 hectares) in organic vegetable production in 2005 for the entire province. So this would represent something like a fivefold expansion in organic acreage over a 10 -year period. MacRae, Martin, Juhasz, \& Langer (2009) concluded that with the proper policy and program supports, the Ontario area devoted to vegetable production could increase to $10 \%$ of total vegetable area or 15,790 acres (6390 ha) of organic production within 15 years. The Toronto program would represent about $36 \%$ of such an expansion.

${ }^{31}$ See for example reports at http://www.agofthemiddle.org/.
}

cases, refrigerated transport. Fixed or mobile smallor medium-scale post-harvest handling facilities would save the costs of creating large centralized facilities, unless an existing partner provides access to them.

Neighborhood hubs for urban agriculture could make food processing possible at a financially viable scale. The link needs to be made between growers and certified commercial kitchens where food can be processed according to Public Health requirements. Processed food could be sold directly at farmers' markets, ensuring some cost recovery.

In addition to neighborhood hubs, larger facilities for processing locally grown food could ultimately be important. A well capitalized Toronto business incubator could stimulate local agricultural production and keep money in the Toronto economy. Existing infrastructure in schools, community centers, and churches could also be used in a more systematic manner to boost food processing.

\section{Distribution Challenges}

About $25 \%$ of U.S. greenhouse gas emissions related to food transport are associated with the delivery of food to consumers, and the percentage may be higher in Canada. These emissions are particularly problematic in the produce sector because of its reliance on trucks (Weber and Matthews, 2008). If small producers move their produce to market in small vehicles, emissions on a tonmile/tonne-km basis will be dramatically higher than imported goods, and all the effects will be felt more in Toronto, even if emissions are reduced along the long-distance supply chain that local production has replaced. Other distribution models, thus, are needed.

Most of the land identified in the MacRae, Gallant et al. (2010) study is located some distance from food retailers, restaurants, and farmers' markets, largely in pockets identified by Lister (2007) as "food deserts" (areas in which very few retail outlets sell fresh food). Most commercial rooftop production would take place in industrial areas, often equally removed from retail locations outside 
the downtown core, as the city's survey (Banting et al., 2005) identified primarily industrial and commercial rooftops as suitable locations (see these three articles for maps). Yet both of these spaces offer distribution possibilities. The larger farms in northeastern Scarborough, likely growing mainly late-season crops, offer opportunities to coordinate collection and distribution. Similarly, many of the small parcels and rooftops in Etobicoke would lend themselves to clustering for distribution purposes.

A sophisticated and multilayered distribution approach is required to account for the diversity of locations, types of production sites, and endbuyers. A key element of the strategy is to avoid, as much as possible, central distribution and packaging. The first layer of distribution would be neighborhood-based, designed to counter what appears to be a relatively recent urban trend of consumers travelling further within a city to obtain their food (Department for Environment, Food and Rural Affairs (DEFRA), 2005). Many landbased production sites in central and north Etobicoke are very accessible to residential areas. Community supported agriculture (CSA), ${ }^{32}$ box schemes, and neighborhood markets may work very well in these areas, with short-haul bicycle ${ }^{33}$ and taxi delivery to local shops and restaurants. Similarly, many potential rooftop sites are concentrated immediately west of the downtown core in districts zoned commercial (Banting et al., 2005), lending themselves to both neighborhood and short-haul distribution scenarios.

\footnotetext{
32 This is an arrangement where consumers prepurchase a share of a farm's produce, which comes in the form of a weekly delivery.

33 The Growing Home project, based in Chicago, offers the services of West Town Bikes to deliver CSA shares to members via bicycle. West Town Bikes is a nonprofit organization whose missions are to promote bicycling in Chicago and to educate youth with a focus on underserved populations. They have a delivery fee on a weekly basis and also offer to pick up compost for a weekly fee. See the website at http://www.urbanhabitatchicago.org/blog/pedaltotablebridging-the-gap-between-local-food-local-transportation/.
}

The mid-range distribution layer involves movement from larger and non-neighborhood sites into mid- and uptown locations, especially restaurants and independent retail, and the Ontario Food Terminal. The longer-range layer involves movement of food from the northwest and northeast into the downtown core. The mid- and long-range scenarios require distribution innovation. Clearly, moving away from the dominant model of largeunit distribution centers can reduce energy use in transport, but having small-scale producers deliver individually to a local distribution center will likely increase energy use relative to the current dominant model (Ministry of Agriculture, Food and Farming (MAFF), 2000).

A new distribution model is $100 \mathrm{~km}$ Foods, which follows a relatively set route around the edge of the city, collecting small batches from different producers and selling to restaurants on different delivery days. This approach appear to reduce emissions relative to traditional methods of trucking. ${ }^{34}$ It represents a promising piece among a whole set of innovations that will be needed to present an effective alternative to the current dominant long-distance distribution system.

\section{Marketing}

Most commercial production will likely be targeted to fresh-food markets, given the growing popularity of local and fresh food. This approach will help maximize market returns for producers. It is the experience of many organizations promoting local food that mainstream retailers or food service operations are not likely to buy Toronto produce. ${ }^{35}$ The main sales opportunities include farm stands, farmers' markets, Good Food Markets, produce auctions, mobile produce carts, home-delivery box schemes, and CSAs. Some independent and cooperative retailers that have flexible vendor protocols and no requirements for central warehousing are also possible outlets.

\footnotetext{
${ }^{34}$ Estimates on file with the corresponding author.

35 This is the experience of Local Food Plus, for which the corresponding author is a consultant.
} 
Independent restaurants, especially those that design their menus around seasonal food, may represent a major potential market, particularly if direct delivery is offered. There may also be opportunities for microprocessors working in small batch operations (including incubator kitchens).

Institutional procurement may be possible for cityrun or city-managed operations. Toronto City Council adopted a Local Food Procurement Policy in 2008 in an attempt to reduce greenhouse gases caused by importing food from afar. To date, however, standards are not in place to describe precisely what "local" means, and shifting supply chains are proving challenging because of existing relations with distributors and the particular food requirements that exist in many cafeterias. In addition, linkages with potential urban growers are needed, which requires partnerships among NGOs, the city, and growers.

\section{Planning, Coordination, Marketing, and Services}

Kaufman and Bailkey (2000) identified the critical need for collaboration among urban farmers. Scaling up urban agriculture in a financially sustainable manner means increasing supply in a coordinated way to keep prices stable and build market confidence in urban suppliers. Although some individuals and organizations may successfully grow food for profit, working together in a co-operative manner is a more likely path to success in Toronto. Land requirements, the dispersion of small parcels across wide areas of the city, and market specialization are all factors that lend themselves to people working together. An urban growers' co-operative could be a step forward. Although a full feasibility study, including what co-op model to employ, will be required, ${ }^{36}$ we suggest a co-op would need to do the following:

- Purchase inputs and equipment and distribute products. The challenges of postharvest handling might also be addressed, including the provision of field-chilling

\footnotetext{
36 This can be co-financed by co-operative development funds available at the provincial and federal levels.
}

facilities (fixed or mobile), supports for packaging, and scheduling of transport.

- Identify opportunities for import substitution or new markets not currently served by existing Ontario producers, and coordinating supply to serve those markets.

- Engage in certain retail functions. For example, it could employ the approach used by the Niagara Food Co-operative, a selfdescribed "virtual farmers' market" where members order food and pay online, picking up their purchases at a central location.

- Develop a "Grown in Toronto" label. ${ }^{37}$ Clearly, detailed market research would be needed before any label is developed. Buy-in from growers, institutional purchasers, and retail outlets would also be required. However, a co-op could learn from the example of Local Food Plus (LFP), a certifying body for sustainably produced local food.

- Educate consumers about the value of local products.

\section{Knowledge Infrastructure}

\section{Training Initiatives}

Toronto has a growing number of students and researchers focusing on urban agriculture, and there are strong links among individuals in its postsecondary institutions. However, dissemination of the knowledge generated by researchers to practitioners is much weaker. Dozens of studies have been undertaken, but most urban farmers are not aware of or do not know how to find them. Internships, sponsored research, and regular presentations can strengthen the links between researchers and growers.

Much knowledge diffusion takes place through training provided by the NGO sector. Still, training

\footnotetext{
${ }^{37}$ Such a label has been created successfully in Detroit, for instance.
} 
of potential urban growers can be enhanced through such means as the successful Toronto Community Food Animators program, facilitated by the city of Toronto. Its functions can be expanded to new parts of the city and to help build community urban agriculture hubs.

Another opportunity lies in adapting the successful Collaborative Regional Alliance for Farmer Training (CRAFT) program for training new farmers across Ontario. An "urban CRAFT" program could support new urban farmers - both young, Canada-born, usually urban-bred individuals, and also recent immigrants who are seeking to make use of their roots in farming but require knowledge to adapt to their new agricultural conditions. A new initiative to coordinate trainers based in the civil society sector and postsecondary educators may soon be launched in Toronto.

The creation of positions for urban agricultural extension specialists, as exist in the departments of agriculture in several U.S. states, is worth considering in Ontario. For example, Penn State University and Cornell University provide agricultural extension agents in Philadelphia and New York City, respectively, offering support to urban community gardens and commercial start-up farms on the cities' peripheries. Toronto city and civil society staff members would need to explore with the Ontario Ministry of Agriculture, Food and Rural Affairs how to develop this capacity for the long term.

MacRae et al. (2009) proposed an organic transition advisory service, modeled on existing Ontario NGO initiatives and successful programs from Europe. Personal assistance from trained experts (often farmers and former organic inspectors) is needed to help farmers explore problems and possible options of which they might otherwise not be aware. U.S. surveys have found that a strong majority of farmers believe that farm planning requires more information than most farmers have at their fingertips, and that advisory services help farmers explore problems and unfamiliar options. MacRae et al. (2009) proposed that the province invest significantly in organic advisory services, sharing the cost among farmers themselves. Should this not come to pass, it would fall on the municipality to finance this function, the most efficient scenario being engagement of an existing thirdparty organization with expertise to deliver the program. Costs would be relatively low given our estimate that up to 1,596 acres (646 ha) would be targeted for the transition: 311 acres (126 ha) currently in conventional vegetables and up to 1,285 acres (520 ha) in corn, soybeans and small grains. $^{38}$

\section{Urban Agriculture Virtual Clearinghouse and Learning Centres}

MetroAg - Alliance for Urban Agriculture (MetroAg), a new North American organization, is currently constructing a clearinghouse on urban agriculture information across Canada and the United States. Sustain Ontario, fast emerging as a key node for improving the province's food and farming systems, recently launched its knowledge platform for the local food movement across Ontario. Toronto is well positioned to develop a Toronto-focused clearinghouse on urban agriculture that would partly interact with the platforms of MetroAg and Sustain Ontario. This would seek to facilitate knowledge sharing among Torontonians and with other urban growers across Ontario and North America. The proposed Toronto clearinghouse would be a systematic source of information on who is doing what in urban agriculture in and around Toronto, including inventories of available lands potentially usable for food production. City regulations as they pertain to local food production and related activities such as composting will form another information set expected to be housed on this site.

Complementing such a digital knowledge clearinghouse, MetroAg and FoodShare have recently created a physical hub within the city, in order to develop and disseminate knowledge about urban agriculture. The Toronto Urban Food and Agri-

\footnotetext{
${ }^{38}$ Because of data confidentiality provisions in Statistics Canada data, we were not able to cross-reference census farms with our mapping (see MacRae, Gallant, et al., 2010). Projected converting hectares may actually be lower than estimated.
} 
Table 2. Models for Municipal Urban Agriculture Development

\begin{tabular}{|c|c|c|c|c|}
\hline Model & Characteristics & Example & Strengths & Limitations for Toronto \\
\hline $\begin{array}{l}\text { Political level } \\
\text { coordination }\end{array}$ & $\begin{array}{l}\text { Mayor's office or } \\
\text { council advocate }\end{array}$ & $\begin{array}{l}\text { Homegrown } \\
\text { Minneapolis }{ }^{a} \text { (initiative } \\
\text { of the mayor, 2009) }\end{array}$ & $\begin{array}{l}\text { Clear political } \\
\text { champion }\end{array}$ & $\begin{array}{l}\text { Not historically an } \\
\text { interest of the mayor's } \\
\text { office; not a strong } \\
\text { mayor system }\end{array}$ \\
\hline $\begin{array}{l}\text { Interdepartmental } \\
\text { committee (IDC) }\end{array}$ & $\begin{array}{l}\text { Representatives from } \\
\text { key implementing } \\
\text { departments }\end{array}$ & Philadelphiab & $\begin{array}{l}\text { Coordinates actions } \\
\text { across civil service }\end{array}$ & $\begin{array}{l}\text { IDC exists }{ }^{c} \text { but cannot } \\
\text { integrate with external } \\
\text { actors }\end{array}$ \\
\hline Leading NGO & $\begin{array}{l}\text { NGO central to policy } \\
\text { and programming in } \\
\text { community }\end{array}$ & $\begin{array}{l}\text { Southside Community } \\
\text { Land Trust, Providence, } \\
\mathrm{RI}^{\mathrm{d}}\end{array}$ & $\begin{array}{l}\text { Strong program } \\
\text { delivery model }\end{array}$ & $\begin{array}{l}\text { No Toronto NGO has } \\
\text { urban agriculture as its } \\
\text { main activity }\end{array}$ \\
\hline Coalition & $\begin{array}{l}\text { NGOs and other actors } \\
\text { working collaboratively }\end{array}$ & $\begin{array}{l}\text { Milwaukee UA } \\
\text { Networke }\end{array}$ & $\begin{array}{l}\text { Brings together diverse } \\
\text { array of actors }\end{array}$ & $\begin{array}{l}\text { Toronto Urban Growers } \\
\text { lacks resources and } \\
\text { depends fully on } \\
\text { volunteers }\end{array}$ \\
\hline
\end{tabular}

a http://www.minneapolismn.gov/health/homegrown/index.htm.

b http://www.leadershipforhealthycommunities.org/images/stories/philadelphia_food_charter1.pdf.

c The committee includes representatives from City Planning; Economic Development, Culture and Tourism; Parks, Forestry and Recreation; Social Development, Finance and Administration; Toronto Community Housing Corporation; and the Toronto Environment Office.

d http://southsideclt.org/.

e http://www.mkeurbanag.org/Main/AboutMUAN.

culture Learning Centre is intended to serve researchers, practitioners, advocates, and others through a hub that would include a physical and digital library that builds on the collections of The Urban Agriculture Network (TUAN), ${ }^{39}$ meeting spaces, and work space.

In addition to a central focal point for knowledge storage and sharing, a series of smaller-scale neighborhood hubs for urban agriculture are needed. Such centers would offer training sessions on urban agriculture, a small library, and a forum for innovation and dissemination of advances. The intention would be to combine such hubs with tool lending and material storage (see the section on physical infrastructure). Neighborhood hubs could be linked to emerging neighborhood food center proposals, which are part of the city's Food Strategy discussions (Toronto Public Health, 2010).

\footnotetext{
${ }^{39}$ MetroAg has secured control of the library that was assembled by TUAN, a nonprofit organization based in Washington, D.C., and has shipped it to Toronto. This collection contains publications, books, articles, papers, computer files, photographs, and recordings.
}

\section{Governance, Coordination and Financial Support Infrastructure}

Complex policy and program environments, such as those related to urban agriculture, are challenging to govern. A governance structure must express and refine a shared vision and enhance long-term plans for implementation. It must aggregate resources for implementing urban agriculture across numerous complementary and competing actions and actors.

Since urban agriculture, especially its commercial expression, is not particularly common in Canadian cities, many of the rules governing its operations have yet to be determined. Gaps in jurisdictional and regulatory frameworks can create governance challenges. The range of landowners and building owners and the geographic dispersion of production and distribution further complicate the governance environment.

Several models for governing this kind of work were investigated and assessed using organizational ecology frames (table 2 and Nasr et al., 2010). We concluded that none of them was appropriate 
given Toronto's current realities. Instead, we turned to the model of a multistakeholder steering body with staffing from a funded agency. From our survey of urban agriculture development in North American cities, no other jurisdiction has completely pursued this model, although a Toronto food-related initiative has used this approach for more than 10 years. The Toronto Partners for Student Nutrition coordinates the implementation of student nutrition programs for 125,000 children daily in Toronto schools. The partnership involves all the major funders and implementers of student nutrition programs, with staff support provided by the Toronto District School Board.

In this model, overall governance and policy development would be provided by a steering body representing all the main governmental and nongovernmental actors engaged in the sector and the proposed urban growers' marketing cooperative. Staffing support would be provided from the city of Toronto, likely by staff who sit on the existing urban agriculture interdepartmental committee. The steering body would have an allocations committee that aggregates resources land, finances, inputs, expertise - and distributes them to projects based on one funding application. The allocation committee's members would include representatives from government, funding agencies, private donors, and program delivery agencies.

Currently, funding for urban agriculture in Toronto largely comes from three sources: foundations (funding NGOs), corporations, and two funding programs of the city of Toronto. ${ }^{40}$ Toronto does not have a funding stream dedicated solely to urban agriculture. Other jurisdictions around the world have such streams, on a permanent or onetime basis, for grants to jump-start the sector. London has instituted Capital Growth, an ambitious project related to the 2012 Olympic Games, which has a goal of creating 2,012 new foodgrowing spaces by 2012. This citywide program is being supported within various boroughs by local

40 The two primary funding programs are Live Green Toronto and the Community Services Partnerships (CSP) program. governments. For instance, the Edible Islington program makes small grants of $\mathrm{C} \$ 300$ to $\mathrm{C} \$ 5,000$ to fund projects that will "provide a community benefit." ${ }^{41}$

The survey of entrepreneurial agricultural projects by Kaufman and Bailkey (2000) legitimately raised questions about the financial viability of such initiatives. Although a full financial analysis was beyond the scope of this study, clearly a mix of market and nonmarket revenue sources will be required, particularly in the start-up phases. The municipality will have a significant role to play in enabling and providing grants and loans for startup. Urban farmers will need to tap into existing OMAFRA grant programs for business planning and environmental stewardship assistance, and to press for a dedicated stream focused on their specific needs for the long term. The Co-operative Development Initiative (a federal grant program accessed through the Canadian Co-operative Association and Ontario Co-operative Association) provides grants for co-operative start-up, and local sustainable food initiatives are one of its priorities. Extension support will be critical. The municipality will have a substantial role in trying to keep costs reasonable, especially land and input costs. Agricultural land taxation rates will probably be essential. Land leasing costs will likely have to remain below fair market value. The proposed Toronto Urban Farmers Marketing Cooperative will play a key role in marketing and distribution, taking some of that burden off individual farmers. But ultimately, farmers will have to survive financially by relying primarily on sales of their produce to create a sustainable food production scenario.

\section{Conclusion}

The potential for urban agriculture is nowhere near being fully realized, but Toronto is ripe for greater urban agricultural activity. Suitable growing spaces may not be the major limiting factor to reach the goal of producing $10 \%$ of Toronto's current fresh vegetable intake. Much of the current activity is small in scale and not necessarily targeted to

${ }^{41}$ See http://www.capitalgrowth.org/. 
Toronto markets. Considerable barriers to scaling up have been identified, and a coherent, coordinated and multi-actor set of policy and program initiatives will be required.

We have proposed a program with five key pillars: infrastructure for accessing spaces for production; resources, services and physical infrastructure; food-chain infrastructure; knowledge infrastructure; and governance, coordination and financial support infrastructure. These five pillars build on existing initiatives and will require a high level of collaboration between multiple actors. The cooperative organizational approach, consistent with organizational ecology frameworks, provides a well proven democratic governance model. The plan involves progressive implementation over a 10 -year period, focuses on import substitution to minimize competition with Ontario producers, actively facilitates demand-supply coordination, and meets other municipal objectives regarding environmental improvement, a livable city, and employment opportunities. The primary role of the state is to reshape the conditions of the market to account for the public benefits that should flow from an urban food production system.

Although designed specifically for the Toronto context, many of the program elements elaborated here are likely to be pertinent to other municipalities, and many planning-related instruments that can be brought to bear on policy and program implementation (Oswald, 2009) are applicable in other jurisdictions. Many other cities in North America are similarly poised to implement commercial urban agriculture programs on a comprehensive scale (see for example, Quinn, 2010, and Stringer, 2010, on New York City). Foodshed thinking increasingly informs this municipal interest, and urban planners are increasingly attentive to issues related to food production. There would appear, as a result, to be great opportunities for widespread scaling-up of food production in cities, including Toronto, if this proposed program were implemented.

\section{Acknowledgements}

Many thanks to the Metcalf Foundation for its support of this research, and to Philippa Campsie for editorial work that significantly enhanced the accessibility of the document. Thanks as well to numerous Toronto-based reviewers who offered important observations on the Metcalf paper. Finally, we're grateful to JAFSCD anonymous reviewers for their feedback on this paper.

\section{References}

Agriculture and Agri-Food Canada (AAFC). (2007). Potato situation and trends 2006-07. Ottawa: Author.

Agriculture and Agri-Food Canada (AAFC). (2008). An overview of Canadian agriculture and agrifood. Ottawa: Author.

Banting, D., Doshi, H., Li, J., Missios, P., Au, A., Currie, B. , \& Verrati, M. (2005). Report on the environmental benefits and costs of green roof technology for the city of Toronto. Report to the city of Toronto and Ontario Centres of Excellence - Earth and Environmental Technologies (OCE-ETech). Toronto: Ryerson University. Retrieved from http://www.toronto.ca/ greenroofs/pdf/fullreport103105.pdf.

Caggiano, C., Dowdall, E., Kwan, C., \& Wagner, A. (2009). Farming in Philadelphia? A proposal for a sustainable urban farm incubator. Panorama, 27-31. Retrieved from http://www.design.upenn.edu/files/Panorama09 08_FarmIncubator_Caggianoetal.pdf.

City of Toronto. (2005). Making green roofs happen. Toronto: City of Toronto. Retrieved from http://www.toronto.ca/greenroofs/policy.htm.

City of Toronto. (2008, April). Ahead of the storm: Preparing Toronto for climate change - bighlights. Toronto: Toronto City Council.

City of Toronto. (2009, May). Identifying urban agriculture opportunities in the city of Toronto. Report to Parks and Environment Committee from L. Oates and B. Patterson. Toronto Environment Office and Department of Parks, Forestry, and Recreation.

Danyluk, M. (2009). Cultivating potential: Planning for urban agriculture in Toronto's bydro corridors. Current Issues Paper Final Report. Toronto: University of Toronto, Geography Department.

Department for Environment, Food and Rural Affairs (DEFRA). (2005). The validity of food miles as an indicator of sustainable development (Report No. ED50254). Retrieved from http://statistics.defra. gov.uk/esg/reports/foodmiles/default.asp. 
Desjardins, E., MacRae, R., \& Schumilas, T. (2010). Linking future population food requirements for health with local production in Waterloo, Canada. Agriculture and Human V alues, 27(2), 129-140. http://dx.doi.org/10.1007/s10460-009-9204-y.

Edward-Jones, G., Milà i Canals, L., Hounsome, N., Truninger, M., Koerber, G., Hounsome, B., ... Jones, D. L. (2008). Testing the assertion that "local food is best": The challenges of an evidence-based approach. Trends in Food Science and Technology, 19, 265-274.

http://dx.doi.org/10.1016/j.tifs.2008.01.008.

Food and Hunger Action Committee, City of Toronto. (2001). The growing season, phase II. Unpublished report. Retrieved from http://www.toronto.ca/ food hunger/growing season.htm.

Kaill-Vinish, P. (2009). Toronto's green roof policy and rooftop food production. Plan Canada, 49(2), 39-41.

Kaufman, J., \& Bailkey, M. (2000). Farming inside cities: Entrepreneurial urban agriculture in the United States. Working Paper for the Lincoln Institute of Land Policy. Retrieved from http://www.lincolninst.edu/pubs/95 FarmingInside-Cities.

Kloppenburg, J., Stevenson, G. W., \& Hendrickson, J. (1996). Coming into the foodshed. Agriculture and Human Values, 13, 33-42. http://dx.doi.org/10.1007/BF01538225.

Lister, N. M. (2007). Placing food. In J. Knechtel (Ed.). Food. Cambridge, Mass.: MIT Press.

Macey, A. (2006). Certified organic production in Canada 2005. Ottawa: Canadian Organic Growers. Available at: http://www.cog.ca

MacRae, R., Gallant, E., Patel, S., Michalak, M., Bunch, M., \& Schaffner, S. (2010). Could Toronto provide $10 \%$ of its fresh vegetable requirements from within its own boundary? Part I, Matching consumption requirements with growing spaces. Journal of Agriculture, Food Systems, and Community Development, 1(2), 105-127. http://dx.doi.org/10.5304/jafscd.2010.012.008.

MacRae, R. J., Hill, S. B. Henning, J., \& Bentley, A. (1990). Policies, programs and regulations to support the transition to sustainable agriculture in Canada. American Journal of Alternative Agriculture, 5(2), 76-92. http://dx.doi.org/10.1017/S0889189300003325.
MacRae, R., Lynch, D., \& Martin, R. (2010). Improving energy efficiency and GHG mitigation potentials in Canadian organic farming systems. Journal of Sustainable Agriculture, 34(5), 549-580. http://dx.doi.org/10.1080/10440046.2010.484704.

MacRae, R. J., Martin, R. C., Juhasz, M., \& Langer, J. (2009). Ten percent organic within 15 years: Policy and programme initiatives to advance organic food and farming in Ontario, Canada. Renewable Agriculture and Food Systems, 24(2), 120-136. http://dx.doi.org/10.1017/S1742170509002531.

McCallum, C. (2001, June). Code, custom, or collaboration: Mechanisms of farmland protection in the GTA and near Montreal. Presentation at the GTA Forum on Agricultural Land Policy: Debating the Alternatives, Toronto, ON.

McClintock, N., \& Cooper, J. (2009). Cultivating the Commons: An assessment of the potential for urban agriculture on Oakland's public lands. Retrieved from Oakland Food Policy Council website at http://www.oaklandfood.org/home/resources.

Mendes, W., Balmer, K., Kaethler, T., \& Rhoads, A. (2008). Using land inventories to plan for urban agriculture: Experiences from Portland and Vancouver. Journal of the American Planning Association, 74(4), 435-449. http://dx.doi.org/10.1080/01944360802354923.

Ministry of Agriculture, Food and Farming (MAFF). (2000). Energy Use in Organic Farming Systems (Report No. OF0182). London: Author.

Morgan, G. (1989). Organizational choice and the new technology. In S. Wright \& D. Morley (Eds.), Learning works: Searching for organizational futures (pp. 47-62). Toronto: ABL Group, Faculty of Environmental Studies, York University.

Morley, D., \& Wright, S. (1989). Epilogue: Organizational and Contextual Change. In S. Wright and D. Morley (eds.), Learning Works: Searching for Organizational Futures (pp. 256-278). Toronto: ABL Group, Faculty of Environmental Studies, York University.

Nasr, J., MacRae, R., \& Kuhns, J. (2010). Scaling up urban agriculture in Toronto: Building the infrastructure. Toronto: Metcalf Foundation. Retrieved from http://metcalffoundation.com/wp-content/ uploads/2011/05/scaling-urban-agriculture.pdf. 
Nassauer, J. I., Corry, R. C., \& Cruse, R. M. (2002). Alternative future landscape scenarios: A means to consider agricultural policy. Journal of Soil and Water Conservation, 57(2), A44-A53.

Nielsen Company. (2006, November 20). Review of certified organic food products at retail in Canada. Prepared for the Organic Agriculture Centre of Canada (OACC). Toronto: Neilsen Company.

Oswald, J. (2009). Planning for urban agriculture. Plan Canada, 49(2), 35-38.

Peters, C. J. Bills, N. L., Lembo, A. J. Wilkins, J. L., \& Fick, G. W. (2009). Mapping potential foodsheds in New York State: A spatial model for evaluating the capacity to localize food production. Renewable Agriculture and Food Systems, 24(1), 72-84. http://dx.doi.org/10.1017/S1742170508002457.

Plumptre, T. W. (1988). Beyond the bottom line: Management in government. Halifax, NS: Institute for Research in Public Policy.

Quinn, C. C. (2010). FoodWorks: A vision to improve NYC's food system. New York, NY: New York City Council. Retrieved from http://council.nyc.gov/html/food/files/foodwork s fullreport 1122 10.pdf.

Seccombe, W. (2007, September). A home-grown strategy for Ontario agriculture. Toronto: Toronto Food Policy Council. Retrieved from Ryerson University website at http://www.ryerson.ca/foodsecurity/ definition/resources/OMAFRApolicyshift.pdf.

Solway, J. (1988). Linkage, synergy and high performance economies. Policy Options, 9(9), 15-19.

Statistics Canada. (2001). Food consumption in Canada: Part II (Catalogue no. 32-230-XIB). Ottawa: Statistics Canada. Retrieved May 2010 from http://www.statcan.gc.ca/pub/32-230-x/32-230x2001000-eng.pdf.

Stringer, S. M. (2010). FoodNYC: Blueprint for a sustainable food system. Manhattan, NY: Office of the Manhattan Borough President. Retrieved from http://www.mbpo.org/uploads/policy reports/ mbp/FoodNYC.pdf.
Toronto Public Health. (2010, February). Food connections: Toward a healthy and sustainable food system in Toronto. Toronto: Toronto Public Health. Retrieved from http://www.toronto.ca/health/food connections report.pdf.

True Consulting Group. (2007). Best practices in urban agriculture: A background report for the city of Kamloops to support development of an urban agriculture strategy. Kamloops, BC: City of Kamloops. Retrieved from http://www.fooddemocracy.org/docs/BestPractices Urban $\% 20$ Agriculture.pdf.

Urban Partners. (2007, December). Farming in Philadelphia: Feasibility analysis and next steps. Philadelphia: Institute for Innovations in Local Farming. Retrieved from http://www.spinfarming.com/common/pdfs/ STF inst for innovations dec07.pdf.

Vidoni, M. (2011). Community composting in Toronto: Closing the food-waste loop (Current Issues Paper Final Report). Toronto: Geography Department, University of Toronto.

Walters, C. J., \& Holling, C. S. (1984). Resilience and adaptability in ecological management systems: Why do policy models fail? In G. R. Conway (Ed.), Pest and pathogen control: Strategic, tactical and policy models (pp. 470-479). Chichester, UK: John Wiley.

Weber, C. L., \& Matthews, H. S. (2008). Food-miles and the relative climate impacts of food choices in the United States. Environmental Science and Technology, 42, 3508-3513. http://dx.doi.org/10.1021/es702969f.

Wekerle, G. (2002). Toronto's Official Plan from the perspective of community gardening and urban agriculture. Ontario Planning Journal, 17(4), 25-26. 
Journal of Agriculture, Food Systems, and Community Development ISSN: 2152-0801 online www.AgDevJournal.com 